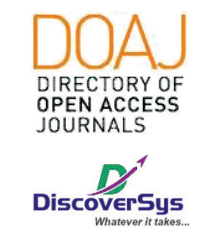

Published by DiscoverSys

\section{Gambaran umum depresi pasca stroke di Poliklinik Neurologi RSUP Sanglah tahun 2015}

\author{
Hilda Citrajaya, ${ }^{1 *}$ Anak Agung Sri Wahyuni ${ }^{2}$
}

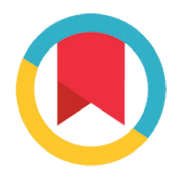

CrossMark

\title{
ABSTRACT
}

Background: Nowadays, stroke is one of the leading causes of death globally. Defects caused by a stroke such as weakness or paralysis of the body cause the patient can not undergo normal daily activities. Depression can be a factor that slows the process of recovery or rehabilitation of stroke patients and it is very important to be prevented before it gets worse.

Aim: To assess the general characteristics of post-stroke depression in Neurology Outpatient Clinic of Sanglah Hospital.

Methods: The design of this research is descriptive with cross sectional study design. The Beck Depression Inventory (BDI) questionnaire was used as an instrument of data collection in this study. The study was carried out in Sanglah Hospital Neurological Clinic on 2015.

Results: From 49 respondents, majority were female (29 subjects or $77.6 \%)$ and 15 were male (22.4\%). The results showed that the prevalence of depression reached $34.7 \%$.

Conclusion: Higher prevalence of depression was found in the sample group with age 56-87 (41.7\%), working as a farmer (50\%), with recent or non-school primary education (60\%), income less than 1 million per month (52.9\%), unmarried (100\%), undergoing medical rehabilitation (38.9\%), first episode of stroke (40\%), last episode of stroke more than 180 days (38.4\%) and being hospitalized more than 10 days (39.1\%).
1Program Studi Pendidikan Dokter Fakultas Kedokteran Universitas Udayana

${ }^{2}$ Bagian/SMF IImu Kedokteran Jiwa Fakultas Kedokteran Universitas Udayana/RSUP Sanglah Denpasar Bali

*Correspondence to: Hilda Citrajaya, Program Studi Pendidikan Dokter Fakultas Kedokteran Universitas Udayana

hilda.citrajaya@gmail.com

Diterima: $13-04-2018$

Disetujui: $15-06-2018$

Diterbitkan: 01-08-2020

Keywords: depression, stroke, prevalence

Cite This Article: Citrajaya, H., Wahyuni, A.A.S. 2020. Gambaran umum depresi pasca stroke di Poliklinik Neurologi RSUP Sanglah tahun 2015. Intisari Sains Medis 11(2): 913-917. D0I: 10.15562/ism.v11i2.256

\section{ABSTRAK}

Latar belakang: Dewasa ini, stroke menjadi salah satu penyebab kematian terbanyak secara global. Kecacatan yang diakibatkan oleh stroke seperti kelemahan atau kelumpuhan bagian tubuh menyebabkan pasien tidak dapat menjalani aktivitas sehari-hari dengan normal. Depresi dapat menjadi faktor yang memperlambat proses pemulihan atau rehabilitasi pasien stroke dan hal ini sangat penting untuk dicegah sebelum menjadi lebih parah.

Tujuan: Untuk meneliti gambaran umum depresi pasca stroke di Poliklinik Neurologi RSUP Sanglah.

Metode: Penelitian ini bersifat deskriptif dengan rancangan penelitian potong lintang (cross sectional). Kuesioner Beck Depression Inventory (BDI) digunakan sebagai instrumen pengumpulan data dalam penelitian ini di Poliklinik Neurologi RSUP Sanglah pada periode Maret-Agustus 2015.
Hasil: Dari 49 orang responden, didapatkan mayoritas berjenis kelamin perempuan (29 orang atau 77,6\%) dan 15 orang berjenis kelamin laki-laki (22,4\%). Hasil penelitian menunjukkan bahwa prevalensi depresi mencapai 34,7\%.

Kesimpulan: Prevalensi depresi lebih tinggi ditemukan pada kelompok sampel dengan usia 56-87 (41,7\%), bekerja sebagai petani (50\%), dengan pendidikan terakhir SD atau tidak sekolah (60\%), pendapatan kurang dari 1 juta per bulan (52,9\%), belum menikah (100\%), menjalani rehabilitasi medik $(38,9 \%)$, mengalami stroke pertama kali $(40 \%)$, waktu serangan stroke terakhir $>180$ hari $(38,4 \%)$ dan lama rawat inap $>10$ hari $(39,1 \%)$.

Kata kunci: depresi, stroke, prevalensi

Cite Pasal Ini: Citrajaya, H., Wahyuni, A.A.S. 2020. Gambaran umum depresi pasca stroke di Poliklinik Neurologi RSUP Sanglah tahun 2015. Intisari Sains Medis 11(2): 913-917. D0I: 10.15562/ism.v11i2.256

\section{PENDAHULUAN}

Pada masa kini, stroke menjadi salah satu penyebab kematian terbanyak secara global. Di Indonesia, menurut riset kesehatan dasar tahun 2013 oleh Departemen Kesehatan RI, prevalensi stroke pada usia lebih dari sama dengan 15 tahun yang terdiagnosis tenaga kesehatan atau memiliki gejala adalah sebesar 12,1 permil (8.740 penderita) dari 722.329 populasi sampel. ${ }^{1}$

Setelah mengalami stroke, masalah baru yang harus dihadapi adalah penurunan kemampuan 
menolong diri sendiri dan perubahan kualitas hidup dimana hal ini memliki asosiasi yang kuat dengan terjadinya depresi. ${ }^{2,3}$

Dalam jurnal tinjauan pustaka oleh Hackett dkk pada tahun 2005 disimpulkan bahwa 33\% pasien pasca stroke mengalami depresi (95\% CI 29\%36\%). ${ }^{4}$ Data terbaru oleh Alajbegovic dkk pada tahun 2014 di Bosnia menyebutkan bahwa depresi muncul pada $66,7 \%$ pasien pasca stroke. ${ }^{5}$

Dalam DSM-IV, depresi pasca stroke (selanjutnya disingkat menjadi DPS) didefinisikan sebagai gangguan mood yang disebabkan oleh kondisi medis (dalam hal ini stroke), dengan gejala depresi mirip episode depresi mayor, gejala mania, ataupun campuran. Dua tingkat depresi yang dapat muncul adalah depresi mayor dan depresi minor. Depresi mayor memenuhi gejala sebagai berikut: mood depresi atau kehilangan minat atau kesenangan dalam aktivitas sehari-hari selama lebih dari dua minggu, mood merepresentasikan perubahan dari suasana hati pada batas normal, fungsi sosial, pekerjaan dan edukasi terganggu, dan memenuhi sekurang-kurangnya 5 dari 9 tanda yang diuraikan dalam DSM-IV. Depresi minor memenuhi minimal 1 dan kurang dari 4 gejala tambahan depresi mayor. ${ }^{6}$

Depresi dapat menjadi faktor yang memperlambat proses pemulihan atau rehabilitasi pasien stroke dan hal ini sangat penting untuk dicegah sebelum menjadi lebih parah. Menurut Stefanu Paolucci pada tahun 2008, pada kenyataanya, depresi pasca stroke sering diabaikan, dan hanya sebagian kecil dari pasien yang terdiagnosis dan ditangani. Mengingat betapa pentingnya peran depresi pada pasien stroke, maka penulis merasa perlu untuk mengetahui gambaran kejadian depresi pasca stroke sehingga pendekatan penanganan pada pasien stroke dapat menjadi lebih optimal dan holistik. $^{7}$

\section{BAHAN DAN METODE}

Penelitian ini bersifat deskriptif dengan rancangan penelitian potong lintang (cross-sectional). Jumlah sampel yang diperlukan adalah 41 orang. Kriteria inklusi yang ditentukan adalah pasien penderita stroke yang kontrol di Poliklinik Neurologi RSUP Sanglah Denpasar periode Maret 2015 sampai dengan November 2015, bersedia berpartisipasi sebagai subjek penelitian, dan menandatangani informed consent.

Teknik pengambilan sampel yang digunakan adalah convenient sampling, sesuai kenyamanan peneliti dan pasien hingga jumlah sampel minimum terpenuhi. Kuesioner Beck Depression Inventory (BDI) digunakan sebagai instrumen pengumpulan data dalam penelitian ini.
Data penelitian dianalisis menggunakan perangkat lunak komputer. Hasil pencatatan tingkat depresi kemudian dikelompokkan menurut usia, jenis kelamin, tingkat pendidikan, status pernikahan, pendapatan, pekerjaan, waktu serangan terakhir, stroke berulang, tinggal dengan, rehabilitasi medik, dan lama rawat inap.

\section{HASIL PENELITIAN}

Gambaran karakteristik responden pada penelitian ini meliputi jenis kelamin, usia, pekerjaan, pendapatan, status pernikahan, status rehabilitasi medik, waktu serangan terakhir, ada tidaknya kasus stroke berulang, lama rawat inap, dan skor depresi berdasarkan BDI. Dari 49 orang responden, didapatkan mayoritas 29 orang berjenis kelamin perempuan $(77,6 \%)$ dan 15 orang berjenis kelamin laki-laki $(22,4 \%)$.

Sebagian sampel tidak melakukan konsultasi rehabitilitasi medik dengan bagian rehabilitasi

\section{Tabel 1 Karakteristik responden penelitian}

\begin{tabular}{|c|c|c|}
\hline Karakteristik & & n (\%) \\
\hline \multirow[t]{2}{*}{ Jenis Kelamin } & Laki-laki & $38(22,4 \%)$ \\
\hline & Perempuan & $11(77,6 \%)$ \\
\hline \multirow[t]{2}{*}{ Usia } & $23-55$ & $25(51 \%)$ \\
\hline & $56-87$ & $24(49 \%)$ \\
\hline \multirow[t]{5}{*}{ Pekerjaan } & Sudah tidak bekerja & $14(28,6 \%)$ \\
\hline & Swasta & $11(22,4 \%)$ \\
\hline & Wiraswasta & $6(12,2 \%)$ \\
\hline & PNS & $10(20,4 \%)$ \\
\hline & Petani & $8(16,3 \%)$ \\
\hline \multirow[t]{3}{*}{ Pendapatan } & $<1$ juta/bulan & $17(34,7 \%)$ \\
\hline & 1-5 juta/bulan & $31(63,3 \%)$ \\
\hline & $>5$ juta/bulan & $1(2 \%)$ \\
\hline \multirow{3}{*}{$\begin{array}{l}\text { Status } \\
\text { Pernikahan }\end{array}$} & Menikah & $43(87,8 \%)$ \\
\hline & Cerai/Janda/Duda & $5(10,2 \%)$ \\
\hline & Belum Menikah & $1(2 \%)$ \\
\hline \multirow{2}{*}{$\begin{array}{l}\text { Rehabilitasi } \\
\text { Medik }\end{array}$} & Tidak & $30(61,2 \%)$ \\
\hline & $\mathrm{Ya}$ & $19(38,8 \%)$ \\
\hline \multirow{2}{*}{$\begin{array}{l}\text { Waktu } \\
\text { Serangan } \\
\text { Terakhir }\end{array}$} & $\leq 180$ hari & $36(73,4 \%)$ \\
\hline & $>180$ hari & $13(26,6 \%)$ \\
\hline \multirow{2}{*}{$\begin{array}{l}\text { Stroke } \\
\text { Berulang }\end{array}$} & Tidak & $40(81,6 \%)$ \\
\hline & Ya & $9(18,4 \%)$ \\
\hline \multirow{2}{*}{$\begin{array}{l}\text { Lama rawat } \\
\text { inap }\end{array}$} & $\leq 10$ hari & $24(48,9 \%)$ \\
\hline & $>10$ hari & $25(51,1 \%)$ \\
\hline \multirow[t]{2}{*}{ Skor BDI } & 0-16 Tidak Depresi & $32(65,3 \%)$ \\
\hline & $>16$ Depresi & $17(34,7 \%)$ \\
\hline
\end{tabular}


medik RSUP Sanglah Denpasar (61,2\%) dan mengalami kejadian stroke untuk pertamakalinya $(81,6 \%)$. Lebih dari setengah populasi sampel belum melewati 343 hari pasca kejadian stroke ketika mengisi kuisioner $(79,6 \%)$ dan sebagian besar sampel dirawat inap lebih dari 10 hari di rumah sakit (51,1\%). Menurut jawaban sampel pada kuisioner Beck Depression Inventory yang telah diberikan, ditemukan bahwa 32 sampel (65,3\%) tidak mengalami depresi sementara 17 sampel $(34,7 \%)$ mengalami depresi. Karakteristik responden dapat dilihat pada Tabel 1.

Hasil penelitian menunjukkan bahwa Sampel yang mengisi kuisioner dengan jarak waktu serangan terakhir dan pengukuran tingkat depresi lebih dari 343 hari memiliki prevalensi depresi lebih tinggi (40\%) dibandingkan dengan sampel dengan jarak waktu $\leq 343$ hari $(34,2 \%)$. Sampel dengan lama rawat inap lebih dari 10 hari sejak kejadian stroke memiliki prevalensi depresi lebih tinggi (39,1\%) dibandingkan dengan sampel dengan lama rawat inap $\leq 10$ hari (32\%) (Tabel 2).

\section{PEMBAHASAN}

Pada penelitian ini ditemukan bahwa prevalensi depresi pada populasi sampel mencapai 34,7\%. Hasil yang serupa juga dilaporkan oleh Paolucci dkk. pada tahun 2006 dengan prevalensi 36\% dari 821 populasi sampel dari lingkungan rumah

Tabel 2 Distribusi tingkat depresi terhadap karakteristik sampel penelitian

\begin{tabular}{|c|c|c|c|c|}
\hline & & Tidak Depresi (\%) & Depresi (\%) & Total (\%) \\
\hline \multirow[t]{2}{*}{ Jenis kelamin } & Perempuan & $8(72,7)$ & $3(27,3)$ & $11(100,0)$ \\
\hline & Laki-laki & $23(62,2)$ & $14(37,8)$ & $37(100,0)$ \\
\hline \multirow[t]{2}{*}{ Kelompok usia } & $23-55$ & $17(70,8)$ & $7(29,2)$ & $24(100,0)$ \\
\hline & $56-87$ & $14(58,3)$ & $10(41,7)$ & $24(100,0)$ \\
\hline \multirow[t]{7}{*}{ Pekerjaan } & Sudah Tidak Bekerja/Pensiun & $11(78,6)$ & $3(21,4)$ & $14(100,0)$ \\
\hline & Swasta & $6(60,0)$ & $4(40,0)$ & $10(100,0)$ \\
\hline & Wiraswasta & $4(66,7)$ & $2(33,3)$ & $6(100,0)$ \\
\hline & PNS & $6(60,0)$ & $4(40,0)$ & $10(100,0)$ \\
\hline & Petani & $4(50,0)$ & $4(50,0)$ & $8(100,0)$ \\
\hline & PNS & $6(60,0)$ & $4(40,0)$ & $10(100,0)$ \\
\hline & Petani & $4(50,0)$ & $4(50,0)$ & $8(100,0)$ \\
\hline \multirow[t]{4}{*}{ Pendidikan } & SD/Tidak Sekolah & $6(40,0)$ & $9(60,0)$ & $15(100,0)$ \\
\hline & SMP & $4(80,0)$ & $1(20,0)$ & $5(100,0)$ \\
\hline & SMA & $8(61,5)$ & $5(38,5)$ & $13(100,0)$ \\
\hline & Perguruan Tinggi & $13(86,7)$ & $2(13,3)$ & $15(100,0)$ \\
\hline \multirow[t]{3}{*}{ Pendapatan } & $<1 \mathrm{jt} /$ bulan & $8(47,1)$ & $9(52,9)$ & $17(100,0)$ \\
\hline & 1-5jt/bulan & $22(73,3)$ & $8(26,7)$ & $30(100,0)$ \\
\hline & $>5$ jt/bulan & $1(100,0)$ & $0(0,0)$ & $1(100,0)$ \\
\hline \multirow[t]{3}{*}{ Status pernikahan } & Menikah & $28(66,7)$ & $14(33,3)$ & $42(100,0)$ \\
\hline & Cerai/Janda/Duda & $3(60,0)$ & $2(40,0)$ & $5(100,0)$ \\
\hline & Belum Menikah & $0(0,0)$ & $0(100,0)$ & $1(100,0)$ \\
\hline \multirow[t]{2}{*}{ Rehabilitasi medik } & Tidak & $20(66,7)$ & $10(33,3)$ & $30(100,0)$ \\
\hline & $\mathrm{Ya}$ & $11(61,1)$ & $7(38,9)$ & $18(100,0)$ \\
\hline \multirow[t]{2}{*}{ Tinggal dengan } & Keluarga & $31(64,6)$ & $17(35,4)$ & $48(100,0)$ \\
\hline & Sendiri & $0(0)$ & $0(0)$ & $0(0)$ \\
\hline \multirow[t]{2}{*}{ Stroke berulang } & Tidak & $24(60,0)$ & $16(40,0)$ & $40(100,0)$ \\
\hline & $\mathrm{Ya}$ & $7(87,5)$ & $1(12,5)$ & $8(100,0)$ \\
\hline \multirow{2}{*}{$\begin{array}{l}\text { Waktu serangan } \\
\text { terakhir }\end{array}$} & $\leq 180$ hari & $24(66,7)$ & $12(33,3)$ & $38(100,0)$ \\
\hline & $>180$ hari & $8(61,6)$ & $5(38,4)$ & $10(100,0)$ \\
\hline \multirow[t]{2}{*}{ Lama rawat inap } & 0-10 hari & $17(68,0)$ & $8(32,0)$ & $25(100,0)$ \\
\hline & $>10$ hari & $14(60,9)$ & $9(39,1)$ & $23(100,0)$ \\
\hline
\end{tabular}


sakit di Italia.7 Jumlah ini jauh lebih kecil bila dibandingkan dengan penelitian Alajbegovic dkk. pada tahun 2014 dimana tercatat $66,7 \%$ dari 210 populasi sampel mengalami depresi. Perbedaan ini dapat disebabkan oleh metode penelitian yang berbeda dimana Aljbegovic mengukur dengan Beck Depression Inventory Scale-II pada masa akut (kurang dari 14 hari sejak waktu serangan). ${ }^{5}$

Prevalensi depresi pada sampel laki-laki yang lebih tinggi dibandingkan dengan sampel perempuan seperti yang ditemukan pada studi ini tidak ditemukan pada studi dengan skala besar pada tahun 2004 oleh Erikkson dkk. dimana 16,4\% adalah perempuan dan $12,4 \%$ adalah laki-laki. ${ }^{8}$

Penelitian ini menemukan bahwa sampel usia diatas 56 tahun memiliki prevalensi depresi lebih tinggi dibandingkan dengan sampel berusia $\leq 56$ tahun. Hasil yang mirip terlihat pada penelitian oleh Erikkson dkk. pada tahun 2004 dimana sampel berusia $\leq 64$ tahun $(15,4 \%)$ memiliki prevalensi lebih rendah dibandingkan sampel berusia $\geq 85$ tahun $(16,7 \%)$, namun tidak demikian pada sampel berusia 65-74 (12,4\%) dan 75-84 (14,1\%). ${ }^{8}$

Sampel yang mengalami stroke untuk pertama kalinya sebelum pengukuran memiliki prevalensi depresi lebih tinggi (40\%) dibandingkan dengan sampel yang mengalami stroke berulang $(12,5 \%)$. Hal yang sebaliknya dilaporkan pada penelitian Errikson dkk (2004), dimana sampel dengan stroke berulang memiliki prevalensi depresi lebih tinggi $(16,4 \%)$ dibandingkan dengan sampel yang mengalami stroke pertama kali $(13,6 \%){ }^{8}$

Pada penelitian Alajbegovic dkk. tahun 2014 didapatkan bahwa sampel dengan depresi berat mempunyai rata-rata lama rawat inap terlama dibandingkan dengan sampel dengan depresi yang lebih ringan. ${ }^{5}$ Hal ini diharapkan dapat menjadi penjelasan dari hasil penelitian ini dimana sampel yang dirawat inap lebih dari 10 hari memiliki prevalensi lebih tinggi (39.1\%) dibandingkan sampel yang dirawat inap $\leq 10$ hari (32\%).

Meta analisis yang dilakukan oleh Ayerbe dkk. pada tahun 2013 menyimpulkan bahwa prevalensi depresi pasca stroke merangkak naik dari $28 \%$ pada observasi dibawah 1 bulan pasca stroke, 31\% pada observasi 1 hingga 6 bulan, memuncak menjadi $33 \%$ pada masa 6 bulan hingga 1 tahun dan menja di $25 \%$ pada masa observasi diatas 1 tahun. ${ }^{9}$ Ulasan Paolucci pada tahun 2008 juga menyebutkan bahwa prevalensi depresi pasca stroke meningkat terutama pada minggu-minggu awal serangan, terutama pada 3 bulan pasca stroke, walaupun berangsur-angsur terjadi pemulihan kondisi. ${ }^{7}$

Terlepas dari kejadian stroke, kehilangan pasangan hidup dapat menjadi faktor yang berkontribusi terhadap terjadinya depresi. Orang yang tidak menikah dan tinggal sendiri merupakan populasi yang lebih rentan terhadap depresi dibandingkan populasi yang menikah dan tinggal bersama keluarga karena mempunyai akses lebih baik terhadap dukungan secara sosial. ${ }^{10}$

Penelitian ini mendapatkan bahwa populasi sampel dengan tingkat pendidikan terakhir setara SD ataupun tidak sekolah miliki tingkat depresi tertinggi dibandingkan populasi sampel lainnya. Hal ini konsisten dengan hasil penelitian yang dilaporkan oleh Everson pada tahun 2002 dimana populasi sampel dengan pendidikan terakhir SMP ataupun SD memiliki prevalensi depresi hamper dua kali lipat dibandingkan populasi sampel dengan pendidikan terakhir SMA. ${ }^{11}$

Pada studi meta analisis oleh Lorant dkk. tahun 2002, disimpulkan bahwa pendapatan dan pendidikan yang rendah dapat meningkatkan resiko kejadian depresi dan juga resiko depresi yang persisten. Hal ini sejalan dengan hasil penelitian ini yang menyatakan bahwa kelompok sampel dengan tingkat pendapatan terendah $(<1$ juta/bulan) memiliki prevalensi depresi paling tinggi dibandingkan dengan populasi sampel lain. ${ }^{12}$

Pekerjaan menjadi salah satu faktor resiko depresi dimana populasi yang tidak bekerja mempunya resiko lebih tinggi (OR 1,17) terhadap kejadian stroke dibandingkan populasi yang bekerja. ${ }^{13}$ Pada penelitian ini didapatkan bahwa populasi sampel yang bekerja sebagai petani mempunyai prevalensi depresi tertinggi sementara populasi sampel yang sudah pensiun atau tidak bekerja lagi menempati urutan kedua.

\section{SIMPULAN}

Prevalensi depresi lebih tinggi ditemukan pada kelompok sampel dengan usia 56-87 (41,7\%), bekerja sebagai petani (50\%), dengan pendidikan terakhir SD atau tidak sekolah (60\%), pendapatan kurang dari 1 juta per bulan $(52,9 \%)$, belum menikah (100\%), menjalani rehabilitasi medik $(38,9 \%)$, mengalami stroke pertama kali $(40 \%)$, waktu serangan stroke terakhir $>180$ hari $(38,4 \%)$, dan lama rawat inap $>10$ hari $(39,1 \%)$.

\section{DAFTAR PUSTAKA}

1. Moustafa RR dan Baron JC. Review: Pathophysiology of ischaemic stroke: insights from imaging, and implications for therapy and drug discovery. British Journal of Pharmacology. 2008; 153,S44-S45.

2. American Heart Association. Types of Stroke; 2012 (diakses di www.strokeassociation.org/STROKEORG/ AboutStroke/About-Stroke_UCM_308529_SubHome Page.jsp pada 11 Desember 2014).

3. Gbiri CA dan Akinpelu AO. Quality of life of Nigerian stroke survivors during first 12 months post-stroke. Hong Kong Physiotherapy Journal. 2012; 30,18-24. 
4. Hackett ML, Yapa C, Parag V, dan Anderson CS. Frequency of Depression After Stroke A Systematic Review of Observational Studies. Stroke. 2005;36:1330-1340.

5. Alajbegovic A dkk. Post Stroke Depression. Med Arh. 2014 Feb; 68(1): 47-50.

6. Starkstein SE dan Lischinsky A.Diagnosis, phenomenology and treatment of poststroke depression. Rev Bras Psiquiatr. 2002;24(1):44-9.

7. Paolucci S. The Italian multicenter observational study on post-stroke depression (DESTRO). J Neurol. 2006 May;253(5):556-62.

8. Eriksson M dkk. Self-reported Depression and Use of Antidepressants After Stroke:A National Survey. Stroke. 2004;35:936-941.

9. Ayerbe L, Ayis S, Charles DAW, dan Rudd AG. Natural history, predictors and outcomes of depression after stroke: systematic review and meta-analysis. BJP. 2013, 202:14-21.

10. Taylor WD. Depression in the Elderly. $N$ Engl J Med. 2014;371:1228-36
11. Everson SA, Marry SC, Lynch JW, Kaplan GA. Epidemiologic evidence for the relation between socioeconomic status and depression, obesity, and diabetes. Journal of Psychosomatic Research. 2002; 53:891-895.

12. Lorant $\mathrm{V}$ dkk. Socioeconomic Inequalities in Depression: A Meta-Analysis. Am J Epidemiol. 2003;157-98-112.

13. Weich S dan Glyn L. Poverty, unemployment, and common mental disorders:population based cohort study. BMJ. 1998 Jul 11;317(7151): 115-119.

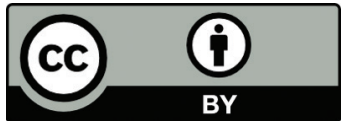

This work is licensed under a Creative Commons Attribution 